\title{
Proposal to Teach Software Development Using Gaming Technique
}

\author{
Amal A. Albilali, Rizwan J. Qureshi \\ Faculty of Computing and Information Technology, King Abdulaziz University, Saudi Arabia \\ Email: amalalbilali@yahoo.com,rmuhammd@kau.edu.sa
}

\begin{abstract}
The world today has witnessed the evolution imposes on researchers in the field of education to review the methods and strategies of teaching, since the teaching and learning system is not a collection of information and knowledge that stuffed in mind. It is a development of cognitive performance and modes of thinking in addition to the use of innovative ways and methods to help the student to adapt to its environment and to solve the problems that he/ she faces to make learning meaningful. One of the recent trends is the use of educational teaching games. Games increase the motivation of the learner and ensure the interaction with educational material which, in turn, offers fun and enjoyable manner in order to achieve the desired objectives. This paper attempts to address the need to utilize gaming to improve learning in active ways and to raise level of the learning process in an interactive environment for the students and the teachers. To evaluate the proposed solution, this paper used survey research methodology and the results are highly encouraging by the professionals working in academia.
\end{abstract}

Index Terms-Games, education, software, castle treasure game.

\section{INTRODUCTION}

The use of games in education is one of the most effective means for grabbing the attention of learners and emphasizes the educational theories. That is to say, drawing attention is more important than encouragement in the learning process, and therefore, the educational games help focus and persist the information in the minds of students.

It is necessary to research, to develop and renew methods of education which are meaningful and useful to provide students with the required skills [1]. Despite the importance of the use of effective methods and activities in the classroom, using Games, it is important to set goals and rule in these activities in order to achieve the main objective, which is the course content in a way the student's education becomes enjoyable and of high quality.

Games would have an effect on the learner and the learning outcomes such as motivation, content mastery and engagement [2]. Educational electronic games divide information into small steps which requires a response and gives immediate feedback, focuses on the educational goal and pushes the learner to continue playing. By playing the learner gets rid of the psychological stress incurred by the educational practices or socializing. Also, he/she integrates knowledge skills such as logical thinking skills, problem-solving skill, the skill of planning and decision-making. On the other hand, Games serve as training for learners to deal with computer hardware and give them experience. Games are an effective tool in individualized instruction and organization to cope with individual differences and the education of learners according to their potential and abilities. The possibility of recurrence of educational games programs to ensure student learning until mastery and perfection stage.

Learning games must include a number of foundations and elements:

- Have a learning objective with a clear and specific goal in conformity with the player who wants to access the game.

- Have rules to determine how to play.

- Rely on the element of competition that may be between one learner and another, or between the learner and the device.

- The game should include a bit of a challenge.

- To excite the imagination of the individual learner and this is what achieves the motivation and desire to learn.

- The game should offer fun, not as the object of the game, but there must be a balance between fun and the educational content.

Rest of this paper is organized as follows. Section II covers related work. Describes the research problem in section III. In section IV, the proposed solution. Validation of the proposed solution is discussed in section $\mathrm{V}$.

\section{RELATED WORK}

It is discussed how to improve and evaluate the student learning by Using the Kinect sensor as interactive technology [3] The objective of the study is to examine the efficiency of the different between the students who learned with (bodily-kinesthetic intelligence) Kinect and the students who learned with the animation (non-bodily kinesthetic intelligence). So, students who learned by Kinect achieved better learning than other students. 
Furthermore, the study needs to improve the Kinect's graphical interface to get more efficiency of the feedback and this study need to implement in a large number of students.

Samáková et al. [4] presented the gaps between the skills that teach in a project management at university and the skills that should be available at a project manager The study tends to analyze how to teach project management. Therefore, it is important to teach the Project Management course in universities in creative and effective ways including theory and simulation. The study gave, as a result, $97 \%$ of the student gained the skills, knowledge and abilities through the teaching with didactic games as an understandable and useful way. But the didactic games must be selected according to certain criteria to assure their efficiency level.

A five-dimensional framework is presented to evaluate simulation games and assessment of usability, player's learning, user experience, and motivation [5]. The objective of this framework is to help designers to evaluate the simulation games. The input of this framework is the educational content and game features; the game features have three steps: user, user behavior and system feedback. But the UGALCO framework needs to be applied in more types of simulation games and try to apply in courses to demonstrate the effective.

A semi-automated serious component based on engineering approach is proposed to introduce educational based games [6]. The proposed approach contains three layers: 1) Interactive wizard interface that takes information from a game developer, preview and edits the game. 2) The user can create components based on serious educational game engine containing four modules: element selection, object creation, game composition and game script output. 3) The repository that contains game assets, game component, and game script. The objective of this approach is to enable educators to rapidly develop their own games in different educational topics. However, the game components are lacking in reusability to use it in any different games.

Longstreet and Cooper [7] proposed a meta-model for developing simulation games in education. The objective of the study is defining the meta-model for educational simulation games to use it on the large scale of disciplines. The meta-model provides several purposes: First, provides a structure for similar categories of game components. Second, allows the facility and designer to change the element of the game component that suits learning objectives. Third, generates a consistent discourse for games education. The validation of the model is limited for this prototyping work. So, it needs additional validation for an external educational game.

According to Tillmann et al. [8] introduced a new platform to address the issue of using traditional ways for assignment grading of the students do not give in time and interactive feedback to them. The platform called Pex4Fun is an interactive gaming based on learning and teaching platform for programming languages like $\mathrm{C \#}, \mathrm{F \#}$ and visual basic. The objective of that platform is to engage students in the social learning environment in an enjoyable way in the field of software engineering at universities, but the platform needs to be applied to different races and ages, and not to be limited to universities.

Dubois and Tamburrelli [9] proposed a research strategy that depended on three activities; analysis activities which identified the appropriate mechanism that applied in different phases of software development, integration activities, and evaluation activities. The aims are to develop this strategy in the context of education of object-oriented software engineering to students at the university by using rules of games. As a result, the strategy is useful and the students who use it get higher marks rather than students indifferently gamified approach. Yet, the study does not mention the detailed game rules or the effect of specific aspects of gamification.

According to Passos et al. [10] proposed a novel approach that shows that the game design concept can be applied to software engineering, and turn software development processes into games, by using achievements as a metric to measure performance. The goal of the approach is to give developers real-time feedback of the game elements, progress and enhances a competition between different teams. But, results of the study are derived from historical data to evaluate the results of a previous study without practical application for the approach.

Ramingwong [11] proposed a CutIT game that aims to teach the process of Improvement in Software Engineering with limited resources and time, and to solve challenges in teaching software engineering. The CutIT designed to be flexible and scalable to deal with different of classes and can be played individually or in the group, also the game divided into five stages: Requirements, Planning, Design, implementation, testing, and deployment. The limitation in this game is the difficulty in disciplining the proposed time in the stages of the game when a large number of students in the class will take a longer time in the application.

Cheong et al. [12] developed an approach in which the gamification is used to enhance and motivate learning by a gamified quiz software tool called (Quick Quiz) that facilitate the game learning activity. The approach was evaluated in three aspects: learning, motivation, and engagement. The limitation of this approach is the activity that used in a short period of time and the result is self-reported.

Barata et al. [13] presented a study of which the various students learn with gamification and how the gaming habits influence the student experience. Data in this study were collected and analyzed for gaming preferences and student performance, from a gamified engineering course (Multimedia Content Production). The study classified students into four types: Achievers who collect the whole achievement in the game; regular students, who have a good performance and avoid some game components; halfhearted students that perform below average in most aspects, and Underachievers, that perform the worst. But the study performed in a small 
sample of students that caused one of the student types to have as few students, so, this makes it difficult to draw any major conclusions from the study.

A 3D game-based on learning system is developed to assist teaching and evaluate the student's motivation, learning achievement and satisfaction [14]. The aim of the study is to enhance software engineering learning, improve traditional education and understand the relationship among learning motivation and achievement. So, this strategy is more effective than traditional teaching ways in learning achievement and motivation.

However, this study lack of evaluation criteria to fill with the learning motivations of students.

Many researchers discussed how the gamification can motivate a person to improve the complex software development [15]. The aims are to offer a clear overview of how the quality of the process can be improved by gamification specifically on software development. Derived from the study, the game elements must be selected in order to enhance internal and external motivation and to understand the problem of people's behavior to successful gamification. Therefore, there is a need for more studies to clear and answer some questions not answered here.

Aydan et al. [16] proposed a 3D serious game for teaching ISO/IEC 12207 Software Lifecycle Process. ISO/IEC 12207 is an international software engineering standard that defines a set of roles and software engineering processes and activates. The objectives of the study are to investigate the possibilities of a 3D serious game that is designed for teaching the basic concepts of ISO/IEC 12207. This study consults a number of experts who work with ISO standards, and offers standards and mechanisms to help in the development of the game and thus to improve the learner of ISO/IEC 12207 standard. But, the study based on a limited number of experts. So, more research should be conducted to evaluate the benefits of the proposed game.

Table 1. Summary of the Related Work

\begin{tabular}{|c|c|}
\hline Title & Limitation \\
\hline $\begin{array}{l}\text { Development and Evaluation of Game-Based } \\
\text { Learning System Using the Microsoft Kinect Sensor } \\
\text { [3]. }\end{array}$ & $\begin{array}{l}\text { The study needs to improve the Kinect's graphical interface to get } \\
\text { more efficiency of the feedback and this study need to implement } \\
\text { in a large number of students. }\end{array}$ \\
\hline $\begin{array}{l}\text { The using of games in education of project } \\
\text { management [4] }\end{array}$ & $\begin{array}{l}\text { The didactic games must be selected according to certain criteria } \\
\text { to assure their efficiency level. }\end{array}$ \\
\hline $\begin{array}{l}\text { Evaluating Software Engineering } \text { Simulation } \\
\text { Games: the UGALCO framework [5] }\end{array}$ & $\begin{array}{l}\text { The UGALCO framework needs to be applied in More types of } \\
\text { simulation games and try to apply in courses to demonstrate the } \\
\text { effective. }\end{array}$ \\
\hline $\begin{array}{llll}\text { Semi-automated } & \text { Serious } & \text { Educational } & \text { Game } \\
\text { Generation [6] } & & & \\
\end{array}$ & $\begin{array}{l}\text { The game components are lacking in reusability to use it in any } \\
\text { different games. }\end{array}$ \\
\hline $\begin{array}{l}\text { Developing a Meta-Model for Serious Games in } \\
\text { Higher Education [7] }\end{array}$ & $\begin{array}{l}\text { The validation of the model limited for this prototyping work. So, } \\
\text { needs additional validation for an external educational game. }\end{array}$ \\
\hline $\begin{array}{l}\text { Teaching and Learning Programming and Software } \\
\text { Engineering via Interactive Gaming [8] }\end{array}$ & $\begin{array}{l}\text { The platform needs to be applied to different races and ages, and } \\
\text { not limited to universities and easy way commensurate with the } \\
\text { level of education, who taught him }\end{array}$ \\
\hline $\begin{array}{l}\text { Understanding gamification } \text { mechanisms for } \\
\text { software development [9] }\end{array}$ & $\begin{array}{l}\text { The study does not mention the detailed of the game rules and } \\
\text { effect of specific aspects of gamification. }\end{array}$ \\
\hline $\begin{array}{l}\text { Turning Real-World Software Development into a } \\
\text { Game [10] }\end{array}$ & $\begin{array}{l}\text { Results of the study are derived from historical data to evaluate } \\
\text { the results of a previous study without practical application for } \\
\text { the approach }\end{array}$ \\
\hline $\begin{array}{l}\text { CutIT: A Game for Teaching Process Improvement } \\
\text { in Software Engineering [11] }\end{array}$ & $\begin{array}{l}\text { The limitation in this game is the difficulty in disciplining the } \\
\text { proposed time in the stages of the game when a large number of } \\
\text { students in the class will take a longer time in the application }\end{array}$ \\
\hline $\begin{array}{l}\text { Quick Quiz: A Gamified Approach for Enhancing } \\
\text { Learning [12] }\end{array}$ & $\begin{array}{l}\text { The limitation of this approach is the activity that used in a short } \\
\text { period of time and the result is self-reported. }\end{array}$ \\
\hline $\begin{array}{l}\text { Relating Gaming Habits with Student Performance in } \\
\text { a Gamified Learning Experience [13] }\end{array}$ & $\begin{array}{l}\text { The study performed in a small sample of students that caused } \\
\text { one of the student types to have as few students, so, this makes it } \\
\text { difficult to drawn any major conclusions from the study }\end{array}$ \\
\hline $\begin{array}{l}\text { 3D game-based learning system for improving } \\
\text { learning achievement in software engineering } \\
\text { curriculum [14] }\end{array}$ & $\begin{array}{l}\text { This study lacks evaluation criteria to fill with the learning } \\
\text { motivations of students }\end{array}$ \\
\hline $\begin{array}{l}\text { Improving the Quality of the Software Development } \\
\text { Lifecycle with Gamification [15] }\end{array}$ & $\begin{array}{l}\text { The study needs for more studies to clear and answered some } \\
\text { question that not answered here }\end{array}$ \\
\hline $\begin{array}{l}\text { Towards a Serious Game to Teach ISO/IEC } 12207 \\
\text { Software Lifecycle Process: An interactive learning } \\
\text { approach [16] }\end{array}$ & $\begin{array}{l}\text { The study based on the limited number of experts, so more } \\
\text { research should be conducted to evaluate the benefits of the } \\
\text { proposed game. }\end{array}$ \\
\hline $\begin{array}{l}\text { A Systematic Survey of Games Used for Software } \\
\text { Engineering Education [17] }\end{array}$ & $\begin{array}{l}\text { The limitation of the study that it didn't follow a true } \\
\text { experimental design and used very small sample sizes. }\end{array}$ \\
\hline
\end{tabular}


A systematic survey for games used in software engineering management education has been presented [17] to show how games can improve education by helping software engineers to explore the complexity of the field in a safe and inexpensive environment. The result of the study was that the students enjoyed playing the games and gained value from the experience and that the educators of software engineering courses must consider using games as a part of teaching. The limitation of the study did not follow a true experimental design and used very small sample sizes.

\section{PROBLEM DEFINITION}

Students of most universities of the world suffer from traditional ways of teaching, due to lack of equipment and experts. This paper attempts to address the need to utilize gaming to improve learning in active ways. Following is the problem identified from the literature review [8] [10] [12] [13].

"How to improve learning and enhance the student motivation in courses by using a game?"

\section{The PRoposed SOLUTION}

Educational games are considered as the modern trends in education technology. They push the learner during the presentation of information to interact with educational materials and with other learners in the educational attitudes. Also, they develop communication skills and increase student's motivation for fun learning and effective manner. This paper proposes Castle Treasure Game that helps to employ the concept of brainstorming within the game by choosing the correct answer in limited time to reach to the treasure, that to help students grasp the information and save it in a competitive and more efficient way. Also, help the teacher to assess the performance of the students. See Fig.1. The proposed solution is based on the following four goals. These goals attempt to utilize the proposed game across a wide variety of courses.

\section{A. Motivate Learners to Generate Creative Ideas About a Particular Subject}

The Instructors can motivate the student to search for the correct answers or possible solutions to the issues presented to them. Thus, through the employment of brainstorming in the educational process, that is, put the mind in a state of excitement and readiness to think in all directions to generate the maximum amount of ideas about the problem or the subject at hand in a period of time. This brainstorming will help students to understand the subject, also assist students to feel more confident. The proposed Game seeks to achieve the following objectives:

- Encourage cooperative education

- Competition among students in groups

- Increase motivation to learn
- Help to realize and understand the information indirectly

- Assist in the evaluation process

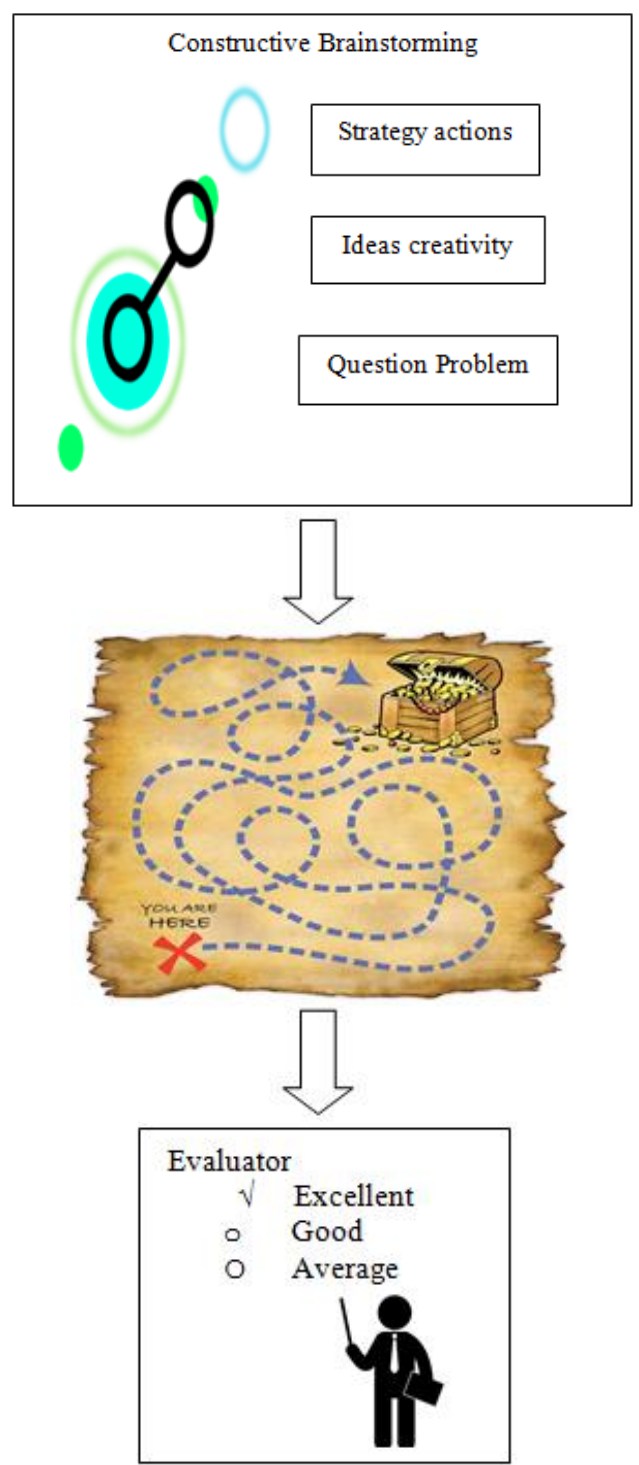

Fig.1. The game life cycle

\section{B. Using castle Treasure Game In Classroom}

Castle Treasure Game is an intelligence game that excites enthusiasm and requests high concentration in order to find the way to reach a treasure as soon as possible. The solution proposed in this paper is to use this game at the end of each lesson or at the end of each unit in the course and it requires to distribute the students in the class into groups and each group will appoint a leader who logs on the game and starts playing. The player is required to reach a treasure before the end of time, and in the castle there are three types of doors:

- $\quad$ Trick door will lead to you out of the castle and must Attempt to access the castle again

- $\quad$ Luck door will make you reach for a Treasure; it is just one in each game 
- The rest of the doors are on your way to gain access to a Treasure, to close the way and to prevent you from going out.

To open the last type of doors you have to answer every question by choosing the correct answer from four answers. But in case, the answer is wrong, the player must search for another path or try again to solve an alternative question in the same door. Principles of the game as follows:

1. Log into the game with a username and password.

2. Questions relating to the course and is renewed automatically so as not to repeat the question twice.

3. In the case of the wrong answer, it will show you the correct answer (feedback).

4. The existence of Game Center, so you can see the rest of the group on the side mini map which increases the spirit of competition, also, you can see the location of yourself.

5. The winner who access to the a Treasure first.

6. In the event, if the team win three times and get to the treasure at halftime of the game, the possibility of withdrawing point will be available than any other group.

7. Finally, treasure points determined by the teacher and collected at the end of the semester.Fig .2 shows the structure of the game.

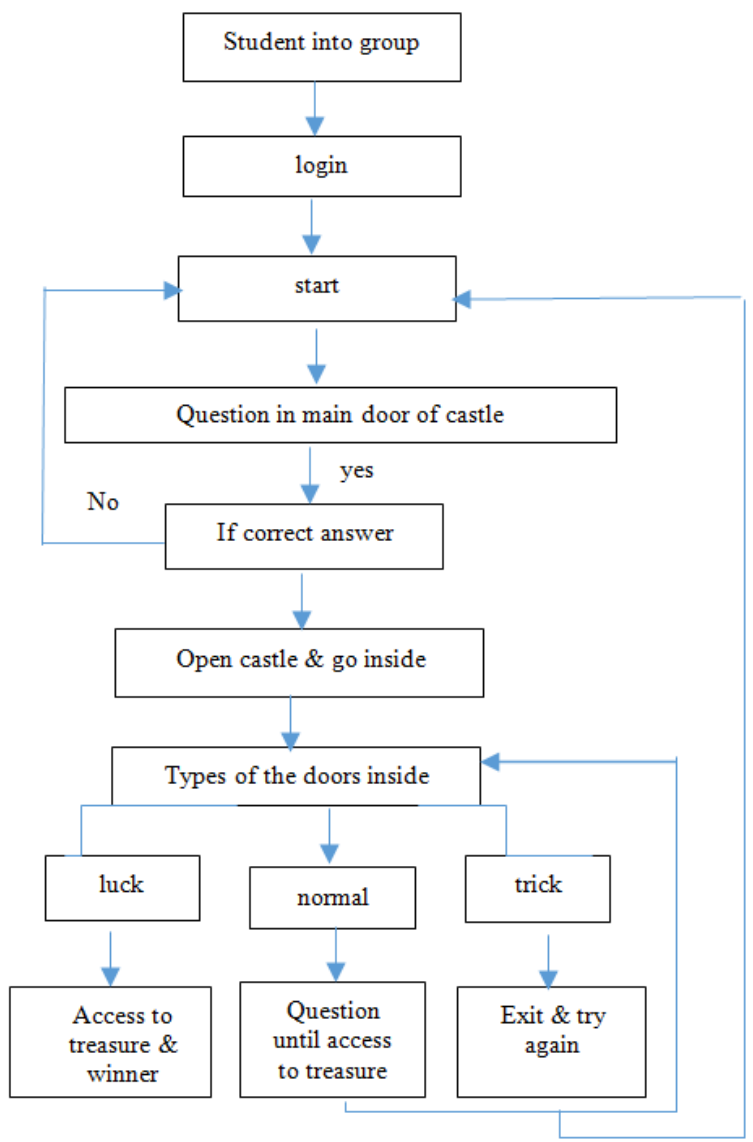

Fig.2. The game structure

\section{Assessing Students based on their Performance in the Game}

This game helps to provide two aspects: measurement and education. The measurement is to enable teachers to gauge students' understanding of the lesson, and to evaluate them based on their performance in the game. Education, in its turn, is to provide the students with information in questions, answers, and feedback if the answer is wrong. And as an incentive and encouragement to the students since the teacher can give the winners at every time points then at the end of the semester, he/she collects points for each group to reward the group with the highest points. This is a motivation for students to learn with fun.

\section{Effect of using Castle Treasure Game in Teaching}

Castle Treasure Game is an intelligent and challenging game that is used to assess students, measures their understanding of the information and increases their desire to focus during the lesson. Using this game will help students to remember the information through questions and answers displayed at every checkpoint.

\section{VALIDATION}

This paper uses the questionnaire method to validate the proposed solution. This method examines the responses of a number of participations and composed of fourteen questions to cover the four goals of proposed solution. Goal 1 is to motivate learners to generate creative ideas about a particular subject. Goal 2 is to use castle treasure game in the classroom. Goal 3 is to assess students based on their performance in the game. Goal 4 is to find out the effect of using castle treasure game in teaching. The questions must be answered in Likert scale of five is used to evaluate the questions from strong disagree to strong agree.

\section{A. Goal 1- Motivate Learners to Generate Creative Ideas About a Particular Subject}

Goal 1 is evaluated by three questions. The results of these questions are shown in table 2 and fig. 3. Table 2 shows that $18.6 \%$ of respondents are strongly agreed to the goal $1.12 .3 \%$ of the professionals are agreed and $7 \%$ of the software engineers remain neutral. $2.3 \%$ of the participants are disagreed to goal 1 .

Table 2. Cumulative analysis of goal 1

\begin{tabular}{|c|c|c|c|c|c|}
\hline Q. No & $\begin{array}{c}\text { Strong } \\
\text { disagree }\end{array}$ & Disagree & Neutral & Agree & $\begin{array}{c}\text { Strong } \\
\text { agree }\end{array}$ \\
\hline 1 & 0 & 3 & 7 & 9 & 22 \\
\hline 2 & 0 & 2 & 5 & 16 & 17 \\
\hline 3 & 0 & 2 & 9 & 12 & 17 \\
\hline Total & 0 & 7 & 21 & 37 & 56 \\
\hline Avg. & 0 & 2.3 & 7 & 12.3 & 18.6 \\
\hline
\end{tabular}




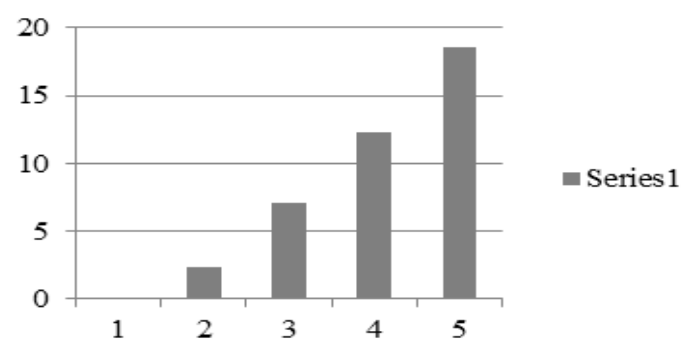

Fig.3. Cumulative Analysis of goal 1

\section{B. Goal 2- using castle Treasure Game in Classroom}

Goal 2 is evaluated by three questions. Table 3 shows the result of goal 2. Table 3 shows that $17.3 \%$ of respondents are strongly agreed to the goal $2.14 .3 \%$ of the professionals are agreed and $6 \%$ of the software engineers remain neutral. $2.6 \%$ of the participants disagree to goal 2. Fig. 4 depicts the results graphically.

Table 3. Cumulative analysis of goal 2

\begin{tabular}{|c|c|c|c|c|c|}
\hline $\begin{array}{c}\text { Q. } \\
\text { No }\end{array}$ & $\begin{array}{c}\text { Strong } \\
\text { disagree }\end{array}$ & Disagree & Neutral & Agree & $\begin{array}{c}\text { Strong } \\
\text { agree }\end{array}$ \\
\hline 1 & 0 & 4 & 6 & 13 & 18 \\
\hline 2 & 0 & 3 & 6 & 16 & 15 \\
\hline 3 & 0 & 1 & 6 & 14 & 19 \\
\hline Total & 0 & 8 & 18 & 43 & 52 \\
\hline Avg. & 0 & 2.6 & 6 & 14.3 & 17.3 \\
\hline
\end{tabular}

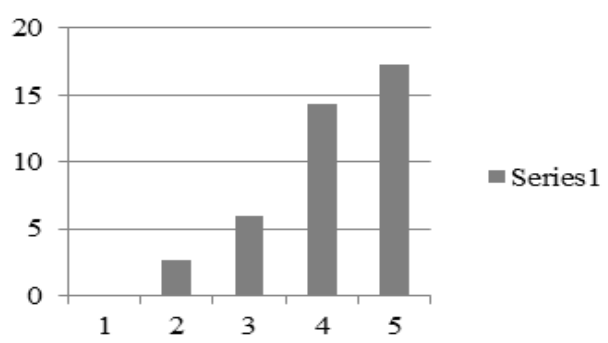

Fig.4. Cumulative Analysis of goal 2

\section{Goal 3- Assessing Students based on their Performance in the Game}

Goal 3 evaluated by four questions in the questionnaire and the results are shown in table 4 . Table 4 shows that $18 \%$ of respondents are strongly agreed to the goal 3 . $13.25 \%$ of the professionals are agreed and $6.5 \%$ of the software engineers remain neutral. $2 \%$ of the participants disagree to goal 3. Fig. 5 shows the results of table 4 graphically.

Table 4. Cumulative analysis of goal 3

\begin{tabular}{|c|c|c|c|c|c|}
\hline Q. No & $\begin{array}{c}\text { Strong } \\
\text { disagree }\end{array}$ & Disagree & Neutral & Agree & $\begin{array}{c}\text { Strong } \\
\text { agree }\end{array}$ \\
\hline 1 & 0 & 2 & 8 & 12 & 18 \\
\hline 2 & 0 & 4 & 8 & 12 & 16 \\
\hline 3 & 0 & 2 & 6 & 16 & 16 \\
\hline 4 & 0 & 0 & 4 & 13 & 22 \\
\hline Total & 0 & 8 & 26 & 53 & 72 \\
\hline Avg. & 0 & 2 & 6.5 & 13.25 & 18 \\
\hline
\end{tabular}

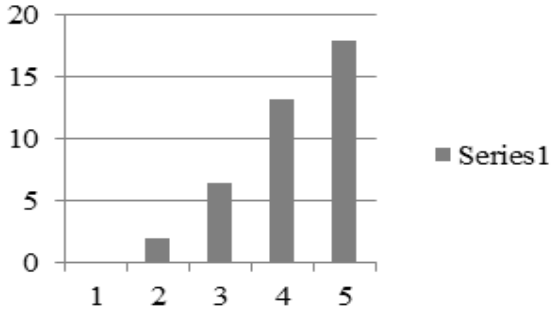

Fig.5. Cumulative Analysis of goal 3

\section{Goal 4- Effect of using castle Treasure Game in Teaching}

Goal 4 is evaluated by four questions and the results are shown in table 5 and fig.6. Table 5 shows that $19.25 \%$ of respondents are strongly agreed to the goal $4.11 \%$ of the professionals are agreed and $7 \%$ of the software engineers are remained neutral. $2.5 \%$ of the participants are disagreed to goal 4.

Table 5. Cumulative analysis of goal 4

\begin{tabular}{|c|c|c|c|c|c|}
\hline $\begin{array}{c}\text { Q. } \\
\text { No }\end{array}$ & $\begin{array}{c}\text { Strong } \\
\text { disagree }\end{array}$ & Disagree & Neutral & Agree & $\begin{array}{c}\text { Strong } \\
\text { agree }\end{array}$ \\
\hline 1 & 0 & 4 & 11 & 7 & 19 \\
\hline 2 & 0 & 0 & 8 & 12 & 19 \\
\hline 3 & 0 & 3 & 5 & 13 & 19 \\
\hline 4 & 0 & 4 & 4 & 12 & 20 \\
\hline Total & 0 & 10 & 28 & 44 & 77 \\
\hline Avg. & 0 & 2.5 & 7 & 11 & 19.25 \\
\hline
\end{tabular}

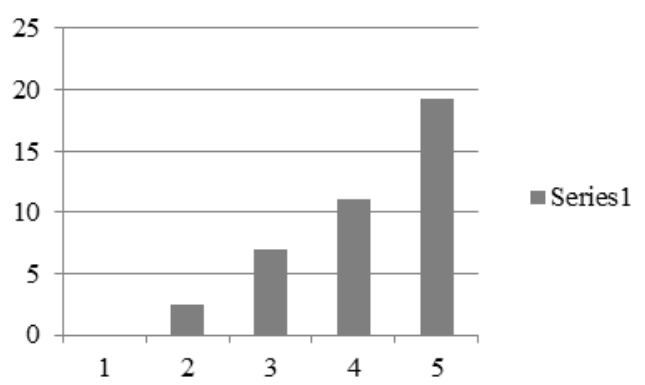

Fig.6. Cumulative Analysis of goal 4

\section{CONCLUSION}

The quest for the development of educational software is one of the most important trends in the modern era; the use of software games in the educational process effectively contributed to increase the motivation of the students and helped to understand the information in a simple and fast way. This paper supports the introduction of interactive methods to provide students with the skills required in the course content rather than the traditional methods of teaching, which lacks to the interactive and interesting methods of teaching. The solution proposed in this paper addresses this problem by four goals. Goal 1 supports motivate the learner to innovate and think in the same way of the innovators who in various topics use the 
teacher's style of brainstorming and make the student's mind looking in all directions to find the right solution, which is connected to the desired goal on time. Goal 2 proposes to use the castle treasure game in which the course will be the content of the game and the student has to pass a series of questions in the fastest time possible. Teacher evaluation to students based on their performance in the game in goal 3. Goal 4 affects of using castle treasure game in teaching. The survey results prove that games increase motivation of the student. Hence, the game based teaching is more effective method to use as an instructional medium as compared to traditional methods of teaching.

\section{REFERENCES}

[1] E. S. Alahmadi, and M. R. J. Qureshi, "Induction of Interactive Methods to Teach Software Engineering Course," Int. J. Mod. Educ. Comput. Sci., vol. 7, no. 6, pp. 43-49, Jun. 2015.

[2] M. F. Young, S. Slota, A. B. Cutter, G. Jalette, G. Mullin, B. Lai, Z. Simeoni, M. Tran, and M. Yukhymenko, "Our Princess Is in Another Castle: A Review of Trends in Serious Gaming for Education,” Rev. Educ. Res., vol. 82, no. 1, pp. 61-89, Mar. 2012.

[3] C.-H. Tsai, Y.-H. Kuo, K.-C. Chu, and J.-C. Yen, "Development and Evaluation of Game-Based Learning System Using the Microsoft Kinect Sensor,” Int. J. Distrib. Sens. Netw., vol. 2015, pp. 1-10, 2015.

[4] J. Samáková, J. Šujanová, R. Beňo, P. Marková, and P. Szabó, "The using of games in education of project management."

[5] D. C. Peixoto, R. F. Resende, and C. I. P. Pádua, "Evaluating software engineering simulation games: The UGALCO framework," in Frontiers in Education Conference (FIE), 2014 IEEE, 2014, pp. 1-9.

[6] R. Daconceicao, C. Locke, K. Cooper, and C. S. Longstreet, "Semi-automated serious educational game generation: A component-based game engineering approach," in Computer Games: AI, Animation, Mobile, Interactive Multimedia, Educational \& Serious Games (CGAMES), 2013 18th International Conference on, 2013, pp. 222-227.

[7] C. S. Longstreet and K. M. L. Cooper, "Developing a Meta-Model for Serious Games in Higher Education," 2012, pp. 684-685.

[8] N. Tillmann, J. De Halleux, T. Xie, S. Gulwani, and J. Bishop, "Teaching and learning programming and software engineering via interactive gaming," in Software Engineering (ICSE), 2013 35th International Conference on, 2013, pp. 1117-1126.

[9] D. J. Dubois and G. Tamburrelli, "Understanding gamification mechanisms for software development," 2013, p. 659 .
[10] E. B. Passos, D. B. Medeiros, P. A. Neto, and E. W. Clua, "Turning real-world software development into a game," in Games and Digital Entertainment (SBGAMES), 2011 Brazilian Symposium on, 2011, pp. 260-269.

[11] S. Ramingwong, "CutIT: A Game for Teaching Process Improvement in Software Engineering,"

[12] C. Cheong, F. Cheong, and J. Filippou, "Quick Quiz: A Gamified Approach for Enhancing Learning," in PACIS, 2013, p. 206.

[13] G. Barata, S. Gama, J. A. P. Jorge, and D. J. V. Gonçalves, "Relating gaming habits with student performance in a gamified learning experience," 2014, pp. 17-25.

[14] S. U. Chung-Ho and C.-H. Cheng, "3D game-based learning system for improving learning achievement in software engineering curriculum," TOJET Turk. Online J. Educ. Technol., vol. 12, no. 2, 2013.

[15] P. Lombriser and R. van der Valk, "Improving the Quality of the Software Development Lifecycle with Gamification," 2011.

[16] U. Aydan, M. Yilmaz, and R. V. O'Connor, "Towards a Serious Game to Teach ISO/IEC 12207 Software Lifecycle Process: An interactive learning approach," in Software Process Improvement and Capability Determination, Springer, 2015, pp. 217-229.

[17] C. Caulfield, J. (Cecilia) Xia, D. Veal, and S. P. Maj, “A Systematic Survey of Games Used for Software Engineering Education," Mod. Appl. Sci., vol. 5, no. 6, Nov. 2011.

\section{Authors' Profiles}

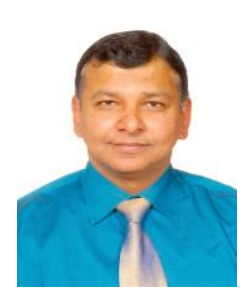

Dr. M. Rizwan Jameel Qureshi received his Ph.D. degree from National College of Business Administration \& Economics, Pakistan 2009. He is currently working as an Associate Professor in the Department of IT, King Abdulaziz University, Jeddah, Saudi Arabia. This author is the best researcher awardees from the Department of Information Technology, King Abdulaziz University in 2013 and the Department of Computer Science, COMSATS Institute of Information Technology, Lahore, Pakistan in 2008.

Amal Abdullah Albilali received her undergraduate degree from Princess Nourah Bint Abdulrahman University. She is currently working as a teaching in the Department of computer science, Majmaah University. She is currently doing master in IT from Faculty of Computing \& Information Technology, King Abdulaziz University, Saudi Arabia

How to cite this paper: Amal A. Albilali, Rizwan J. Qureshi,"Proposal to Teach Software Development Using Gaming Technique", International Journal of Modern Education and Computer Science(IJMECS), Vol.8, No.8, pp.21-27, 2016.DOI: $10.5815 /$ ijmecs.2016.08.03 